九州大学学術情報リポジトリ

Kyushu University Institutional Repository

\title{
Experiments on the Control of Salinity and Sodicity in Surface : Irrigated Fields in the Upper Yellow River Valley (II)
}

Yoshikoshi, Hisashi

Department of Bioproduction Environmental Sciences, Faculty of Agriculture, Kyushu University

Wang, We izhen

Cold and Arid Regions Environmental and Engineering Research Institute

Cho, Hiroyuki

Department of Agricultural Sciences, Saga University

Araki, Takuya

Departmetn of plant Resources, Faculty of Agriculture, Kyushu University

他

https://doi.org/10.5109/10101

出版情報：九州大学大学院農学研究院紀要. 53 (1)，pp.257-263，2008-02-28. Faculty of Agriculture, Kyushu University

バージョン :

権利関係 : 


\title{
Experiments on the Control of Salinity and Sodicity in Surface-Irrigated Fields in the Upper Yellow River Valley (II)
}

\author{
Observation System and Calibration
}

\author{
Hisashi YOSHIKOSHI, Weizhen WANG $^{1}$, Hiroyuki CHO $^{2}$, Takuya ARAKI ${ }^{3}$, \\ Daisuke YASUTAKE ${ }^{4}$, Jian ZHOU' ${ }^{1}$, Kazuki URAYAMA ${ }^{5}$, Yueru WU ${ }^{1}$, \\ Tetsuo KOBAYASHI* and Masaharu KITANO
}

\author{
Laboratory of Applied Meteorology, Division of Regional Environment Science, Department of \\ Bioproduction Environmental Sciences, Faculty of Agriculture, \\ Kyushu University, Fukuoka 812-8581, Japan \\ (Received November 9, 2007 and accepted November 30, 2007)
}

\begin{abstract}
An experimental field was established in Pingbu village extending along the Yellow River (Baiyin, Gansu, China) to conduct experiments on the control of salinity and sodicity in surface-irrigated fields, and an observation system for measuring meteorological and hydrological elements relevant to soil salinization and alkalization was installed in it. The outline of the observation system is shown; principles of measuring such elements are examined and their limitations are pointed out in case of necessity. Furthermore, careful considerations are given to the system so that the system could measure such elements as accurately as possible.
\end{abstract}

KEY WORDS: biological reclamation, irrigation, salinity, soil physical reclamation, sodicity, TDR

\section{INTRODUCTION}

For irrigation agriculture to succeed, salinity and sodicity levels in soils and irrigation water must be controlled. To conduct experiments on the development of effective, soil physical and biological measures for controlling salinity and sodicity in surface-irrigated fields, an experimental field was established in Pingbu, Gansu, China (Wang et al., this issue).

Since the electrical conductivity (EC) of soil solution is linearly related to the total salt concentration, soil salinity can be monitored continuously and automatically in the field by measuring EC with TDR (time domain reflectometry) probes (Wang et al., 2006). As for sodicity, however, it is difficult to measure it (SAR or ESP) automatically in the field (Wang et al., this issue). Therefore, water extracts of soils are used for measuring soil sodicity in the laboratory. In general, however, the saturation extract or dilution extracts such as the extract of a soil sample at 1: $x$ soil-water ratio $(x=1 \sim 5)$ is used (Wang et al., this issue; Yasutake et al., this issue).

${ }^{1}$ Laboratory of Remote Sensing and GIS, Cold and Arid Regions Environmental and Engineering Research Institute, CAS, Lanzhou 730000, China

2 Department of Agricultural Sciences, Saga University, Saga 840-8502, Japan

${ }^{3}$ Laboratory of Plant Production, Division of Soil Science and Plant Production Physiology, Department of Plant Resources, Faculty of Agriculture, Kyushu University, Fukuoka 812-8581, Japan

${ }^{4}$ Faculty of Agriculture, Kochi University, Nankoku 783-8502, Japan

${ }^{5}$ Graduate School of Bioresource and Bioenvironmental Sciences, Kyushu University, Fukuoka 812-8581, Japan

* Corresponding author (E-mail: kotetsu@bpes.kyushu-u.ac.jp)
Salts in soil are transported by soil water, and therefore soil water movement has to be monitored in order to analyze the salt behavior in soil. Thus, it is essential to observe precipitation, soil moisture, groundwater level, and evaporation in the field for conducting experiments on soil salinization processes.

This paper gives the outline of the observation system installed at the experimental field. The principle of the TDR technique and methods of measuring evaporation in the field are also examined, and the results of calibrating this system are shown, which calibration was made so that this system could be used for measuring the variables relevant to this subject as accurately as possible.

\section{INSTRUMENTS}

The experimental field established at Jiangtan section of Pingbu village in Jingyuan, Baiyin, Gansu (N36 ${ }^{\circ}$ 25.5, $\mathrm{E} 104^{\circ} 25.4^{\prime}, 1461 \mathrm{~m} \mathrm{ASL}$ ) is located in an alluvial valley of the Yellow River, and a cliff of the yellow loess about $150 \mathrm{~m}$ high rises about $500 \mathrm{~m}$ southeast of the field. Fig. 1 shows a ground plan of the field, the area being about one mu (Chinese unit of area, $667 \mathrm{~m}^{2}$ ). Although part of the northwest edge shares with the residential lot of the owner of this field, this field is bordered on fields or a narrow road to the other directions.

The arrangement of instruments is shown in Fig. 1 and the general description of the instruments is listed in Table 1. The water diverted from the Yellow River flows through the canal excavated along the road at all times in the growing season and the part of the experimental field close to the canal is severely salinized. Thus, three points for measuring soil moisture and salinity were arranged so that one (P1) was in the severely salinized 
Table 1. Meteorological and hydrological instruments installed in the experimental field

\begin{tabular}{cccc}
\hline Variable & Instrument & Sampling \& averaging $\Delta t$ & Height or depth (m) \\
\hline Air temperature \& humidity & VAISALA, HMP50 & 15 sec \& $10 \mathrm{~min} *$ & $1.8,4.3$ \\
Net radiation & CAMPBELL, Q*7 & As above & 2.8 \\
Solar radiation & CAMPBELL, LI200X & As above & 2.8 \\
Wind speed \& direction & YOUNG, CYG5103 & As above & 6.0 \\
Ground heat flux & REBS, HFT-3.1 & As above & $-0.05,-0.15$ \\
Precipitation & CAMPBELL, TE525 & 10 min (cumulative) & - \\
Soil moisture \& EC & CAMPBELL, CS610 & 30 min (momentary) & $-10,-20,-40,-60$ (P2) \\
Soil temperature & CAMPBELL, MO 107 & As above & $-10,-20,-40$ \\
Groundwater level & CAMPBELL, CS420 & As above & - \\
\hline
\end{tabular}

* On and after 10 Nov. 2007, time period 10 min was changed to 30 min.

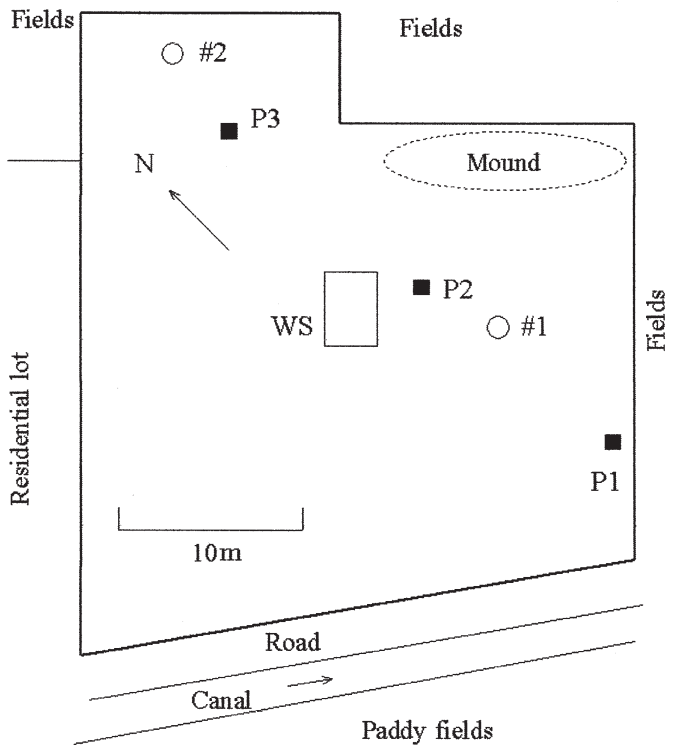

Fig. 1. A ground plan of the Pingbu experimental field WS: weather station, $\bigcirc$ : well, $\mathbf{\square}$ : TDR.

part and the others (P2 and P3) were moderately and slightly salinized parts in the field, respectively (Fig. 1).

Volumetric soil water content $(\theta)$ and bulk soil electric conductivity $\left(\mathrm{EC}_{\mathrm{a}}\right)$ are measured using TDR probes at P1, P2 and P3. Two tube wells were dug in the field (\#1 and \#2). The well \#1 is for not only measuring the groundwater level but also pumping groundwater out, the diameter being $11 \mathrm{~cm}$ and the depth to the bottom end of the perforated pipe being $210 \mathrm{~cm}$ (measurable depth limit $=-193 \mathrm{~cm}$ ). On the other hand, the well \#2 is for observing the groundwater level, the diameter being $8.5 \mathrm{~cm}$ and the depth being $130 \mathrm{~cm}$ (measurable depth limit $=-110 \mathrm{~cm}$ ). In this field, depth to the water table is smaller than $1 \mathrm{~m}$ in the growing season when the canal is filled with irrigation water, though it becomes larger than $1 \mathrm{~m}$ in winter when the canal is dry and precipitation is low (Wang et al., this issue).

A meteorological pole $6 \mathrm{~m}$ high was raised in an meteorological observation field enclosed with a chainlink fence ( $3 \times 5 \mathrm{~m}$, WS in Fig. 1). Wind speed and direction, air temperature and humidity, solar radiation, and net radiation are measured with sensors mounted on the pole (Table 1). A raingage and ground heat flow meters are also set in WS, while soil thermometers were installed at P2.

\section{PHYSICAL PROPERTIES OF THE SOIL}

Physical properties of the soil in the Pingbu experimental field (P1), which is an alluvial soil, are listed in Table 2. Those of the soil in the experimental field established at Togtoh, Inner Mongolia (Wang et al., this issue) are also shown for reference. Fig. 2 shows the matric potential (suction)-water content relation for the Pingbu soil. The curve is a van Genuchten equation fit to the measurements (Jury and Horton, 2004). Fig. 3 shows the matric potential (suction)-hydraulic conductivity relation for the Pingbu soil obtained by the van Genuchten parametric model (Jury and Horton, 2004).

It is obvious from Table 2 that $89.1 \%$ of the Pingbu

Table 2. Physical properties of the soil in the Pingbu field (P1). Those of the soil in the Togtoh field also are shown for reference

\begin{tabular}{lcc}
\hline \multirow{2}{*}{ Particle size $(\mathrm{mm})$} & Pingbu $(\mathrm{P} 1)$ & Togtoh \\
\cline { 2 - 3 } & \multicolumn{2}{c}{$\%$ by weight } \\
\hline$<0.002$ & 14.9 & 10.3 \\
$0.002 \sim 0.075$ & 74.2 & 67.5 \\
$0.075 \sim 0.25$ & 10.9 & 17.3 \\
$0.25 \sim 0.85$ & 0 & 0.2 \\
$0.85 \sim 2$ & 0 & 4.7 \\
Particle density $\left(\mathrm{g} \mathrm{cm}^{-3}\right)$ & 2.71 & 2.70 \\
Dry density $\left(\mathrm{g} \mathrm{cm}^{-3}\right)$ & 1.60 & 1.40 \\
Porosity $(-)$ & 0.40 & 0.50 \\
Saturated hydraulic conductivity $\left(\mathrm{cm} \mathrm{s}^{-1}\right)$ & $3.13 \times 10^{-5}$ & $1.29 \times 10^{-4}$ \\
\hline
\end{tabular}

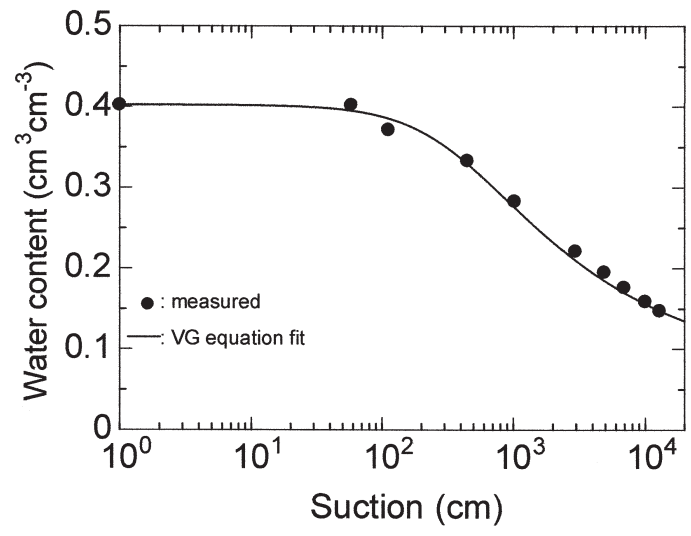

Fig. 2. Matric potential (suction)-water content relation for the soil in this field (P1). The curve is a van Genuchten equation fit to the measurements $\left(\theta_{\mathrm{r}}=0.066, \theta_{\mathrm{s}}=0.40, \alpha=0.028\right.$, $N=1.40$ ). 


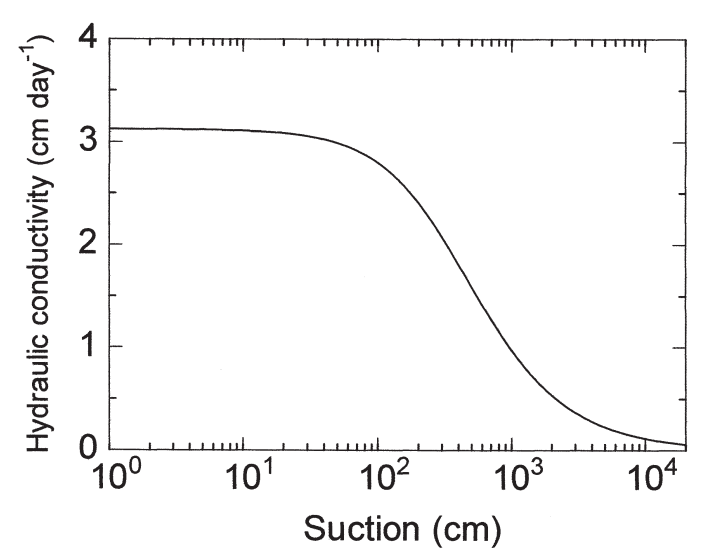

Fig. 3. Matric potential (suction)- hydraulic conductivity relation for the soil in this field (P1) obtained by the van Genuchten parametric model $\left(\theta_{\mathrm{r}}=0.066, \theta_{\mathrm{s}}=0.40, \alpha=0.028, N=1.40\right.$, $\left.K_{\mathrm{s}}=3.13 \times 10^{-5}\right)$

soil is smaller in diameter than $0.05 \mu \mathrm{m}$, while the portion is $77.8 \%$ for the Togtoh soil. Furthermore, the saturated hydraulic conductivity of the Pingbu soil is about an order of magnitude smaller than that of the Togtoh soil. These properties suggest that the Pingbu soil is more susceptible to salinization than the Togtoh soil.

\section{TIME DOMAIN REFLECTOMETRY (TDR)}

\section{Principle}

Time domain reflectometry (TDR) is used for simultaneous measurement of volumetric soil water content $(\theta)$ and bulk soil electric conductivity $\left(\mathrm{EC}_{\mathrm{a}}\right)$ in this field. The measurement of $\theta$ is based on measuring the travel time of an electromagnetic pulse lunched along a transmission line embedded in the soil, while the measurement of $\mathrm{EC}_{\mathrm{a}}$ is based on measuring the impedance of the soil.

The main components of a TDR system are a cable tester, a coaxial connection cable, and the TDR probe. The cable tester sends out a high-frequency electromagnetic pulse $(\sim 1 \mathrm{GHz})$, which travels down the coaxial cable and enters the TDR probe. At both ends of the probe, the pulse is partly reflected back, from which the travel time of the pulse along the probe can be detected.

If $K^{\prime}$ is the real part of the complex dielectric constant $K^{*}$, or

$$
K^{*}=K^{\prime}-i\left(K^{\prime \prime}+\sigma_{\mathrm{dc}} / \omega \varepsilon_{0}\right)
$$

where $i=$ imaginary unit, $\omega=$ frequency of alternating current, $\sigma_{\mathrm{dc}}=$ direct current conductivity, $\varepsilon_{0}=$ permitivity of free space (Takahashi, 1970), the speed $(v)$ of an electromagnetic wave in nonmagnetic material such as soil and solution is approximately given as

$$
v=\frac{c}{K^{1 / 2}}
$$

because $K^{\prime}>>\left(K^{\prime \prime}+\sigma_{\text {dc }} / \omega \varepsilon_{0}\right)$ (Yanuka et al., 1988).

The soil comprises a volume fraction of soil solids, water, and air. Representative values of $K_{a}=\left|K^{*}\right|$ are
80.36 for liquid water, 3-5 for soil materials, $6-8$ for organic matter, and 1 for air at a frequency of $1 \mathrm{GHz}$ and a temperature of $20{ }^{\circ} \mathrm{C}$ (Vogeler et al., 2005). Thus, $K_{a}$ $\left(\sim K^{\prime}\right)$ of a soil is dominated by the content of water because of its high $K_{a}$ value. The relation between $\theta$ and $K_{a}$ can be determined experimentally (Eq.13).

A simple model of the TDR system is used to explain how to measure the impedance of a soil using TDR. The model is described as a coaxial transmission line consisting of two conductors, with a power source (i.e., a cable tester) at one end (say, left) and a load (i.e., the soil sample) having impedance $Z_{L}$ at the other end (right).

The basic equations for a transmission line can be written as (Takahashi, 1970):

$$
\begin{aligned}
& -i \omega C E=\frac{d I}{d x} \\
& -i \omega L I=\frac{d E}{d x}
\end{aligned}
$$

where $C=$ capacitance per length, $L=$ inductance per length, $E=$ the difference in electric potential between the two conductors, $I=$ electric current, $x=$ coordinate along the line (positive rightward). The time dependence of $I$ and $E$ expressed by $\mathrm{e}^{i \omega t}$ is omitted in these expressions.

The solutions to Eq.(3) are given by

$$
\begin{aligned}
& E=E_{+} e^{-\gamma x}+E_{-} e^{\gamma x} \\
& I=I_{+} e^{-\gamma x}+I_{-} e^{\gamma x}
\end{aligned}
$$

where

$$
\gamma=i \omega \sqrt{L C}
$$

and subscripts + and - indicate that the quantities are related to the wave propagating in the right and left direction, respectively. Therefore, characteristic impedance $Z_{0}$ is written as

$$
Z_{0}=\frac{E_{+}}{I_{+}}=-\frac{E_{-}}{I_{-}}=\sqrt{\frac{L}{C}}
$$

If the origin of the coordinate $\mathrm{x}$ is set at the point of the load having impedance $Z_{L}$ or the right end of the coaxial transmission line, the following relation is obtained using Eqs.(4) and (5).

$$
Z_{L}=\frac{E(x=0)}{I(x=0)}=\frac{E_{+}+E_{-}}{I_{+}+I_{-}}=\frac{I_{+}-I_{-}}{I_{+}+I_{-}} Z_{0}
$$

If the reflection coefficient at the right end of the transmission line is designated as $\rho$, then using Eqs. (5) and (6) we get

$$
\rho=\frac{E_{-}}{E_{+}}=-\frac{I_{-}}{I_{+}}=\frac{Z_{L}-Z_{0}}{Z_{L}+Z_{0}}
$$

Since the characteristic impedance $Z_{0}$ is an intrinsic value of the TDR system, if $\rho$ can be measured using TDR, we can get $Z_{L}$ from Eq.(7).

The impedance of a soil is, in general, indicated by a complex number. However, because $Z_{0}$ is a real number (Eq.5), $Z_{L}$ is also regarded as a real number as is obvious from Eq. (6). This is, of course, a result of applying the 
simple model to the TDR system, but the result is approximately true. Since the real part of impedance means the resistance, the TDR-measured impedance $Z_{L}$ can be converted to $\mathrm{EC}_{\mathrm{a}}$ as

$$
\mathrm{EC}_{\mathrm{a}}=f K_{G} Z_{L}^{-1}
$$

where $f$ is a correction coefficient for temperatures $\left(T^{\circ} \mathrm{C}\right.$ ) other than $25^{\circ} \mathrm{C}$ and expressed as (Dirksen, 1999):

$$
f=\frac{1}{1-0.0191(T-25)}
$$

$K_{G}$ is the probe geometry constant and experimentally determined one by one $\left(\mathrm{m}^{-1}\right)$.

In practice, the reflection coefficient $\rho$ is estimated with the "thin sample" equation derived by Giese and Tiemann (Topp et al., 1988) based on the waveform analysis of the TDR trace (Dirksen, 1999).

If $\rho$ is too small, or $Z_{L}$ approaches extremely to $Z_{0}$ due to high soil salinity, the TDR system cannot get the information on the electromagnetic property of the soil. Furthermore, the relation between $\mathrm{EC}_{\mathrm{a}}$ and $Z_{L}^{-1}$ (Eq.8) is based on the assumption that the relation is intrinsically linear. It may be true at least for the electrical conductivity of the soil water $\left(\mathrm{EC}_{\mathrm{w}}\right)$ up to $8 \sim 20 \mathrm{dS} \mathrm{m}{ }^{-1}$, but with higher conductivity, the relation becomes nonlinear (Vogeler et al., 2005).

The degree of nonlinearlity is influenced by the characteristics of the TDR probe, with three-wire sensors being superior to two-wire sensors (Volgeler et al., 2005). In this experiment, the TDR probe consisting of three rods of length $30 \mathrm{~cm}$, diameter $0.48 \mathrm{~m}$, and spacing between rods of $2.2 \mathrm{~cm}$ was used and inserted horizontally into the soil (Table 1).

\section{Models of electrical conduction in soil}

Simultaneous measurements of $\theta$ and $\mathrm{EC}_{\mathrm{a}}$ can be taken with a single TDR probe. However, it would be desirable to know the soil solute concentration in the soil water, or $\mathrm{EC}_{\mathrm{w}}$ over the entire range of the field water contents and to obtain this information directly in the field (Rhoades, 1982). Various approaches to this issue exist.

Wang et al. (2005) adopted a model of electrical conduction in soil suggested by Rhoades et al. (1976) for analyzing soil salinization processes in the Togtoh experimental field, which gives the following relationship:

$$
\mathrm{EC}_{\mathrm{a}}=\mathrm{EC}_{\mathrm{w}} \theta T(\theta)+\mathrm{EC}_{\mathrm{s}}
$$

where

$$
T(\theta)=\alpha \theta+\beta
$$

is an empirical relation expressing a transmission coefficient $(\leqq 1)$ and $\alpha$ and $\beta$ are soil-dependent constants, and $\mathrm{EC}_{\mathrm{s}}$ is the electrical conductivity of the solid phase of a soil due primarily to exchangeable cations adsorbed on clay minerals.

In Eq.(10), the relation between $\mathrm{EC}_{\mathrm{a}}$ and $\mathrm{EC}_{\mathrm{w}}$ is assumed to be linear for a fixed water content. However, at low $\mathrm{EC}_{\mathrm{w}}$ under $1-5 \mathrm{dS} \mathrm{m} \mathrm{m}^{-1}$, a nonlinearity in the $\mathrm{EC}_{\mathrm{a}}-$ $\mathrm{EC}_{\mathrm{w}}$ relation has been observed in some soils. Thus, if the linearity in the $\mathrm{EC}_{\mathrm{a}}-\mathrm{Z}_{\mathrm{L}}{ }^{-1}$ relation (Eq.9) is also taken into consideration, the TDR technique should be applied to soil solutions with a range of $\mathrm{EC}_{\mathrm{w}}$ from about 1 to $20 \mathrm{dS} \mathrm{m}^{-1}$ (Vogeler et al., 2005). If we identify the three parameters $\mathrm{EC}_{\mathrm{s}}, \alpha$ and $\beta, \mathrm{EC}_{w}$ can be estimated from the measurements of $\mathrm{EC}_{\mathrm{a}}$ and $\theta$ made using TDR from Eqs. (10) and (11).

Wang et al. (2005) assumed that the relation between $\mathrm{EC}_{\mathrm{w}}$ and $\theta$ could be written as

$$
\mathrm{EC}_{\mathrm{w}}=\mathrm{EC}_{\mathrm{SAT}}\left(\frac{\varepsilon}{\theta}\right)^{n}
$$

where $\mathrm{EC}_{\mathrm{SAT}}=$ electrical conductivity of the extract of a saturated soil (Kobayashi et al., 2006), $\varepsilon=$ porosity of the soil, $n=$ a parameter to be determined by experiment. When precipitation-dissolution reactions can be neglected, we can set $n=1$, while in general, $0<n \leqq 1$. Thus, $\mathrm{EC}_{\mathrm{SAT}}$ is estimated from $\mathrm{EC}_{\mathrm{w}}$ using Eq.(12) if $n$ is determined by experiment.

\section{Calibration}

Soil samples were collected in the experimental field during a period of 12-13 Aug. 2007, when depth to the water table was about $50 \mathrm{~cm}$ and the EC of the groundwater was about $4 \mathrm{dS} \mathrm{m}^{-1}$. However, the $\mathrm{EC}_{\mathrm{SAT}}$ of the surface soil exceeded $10 \mathrm{dS} \mathrm{m} \mathrm{m}^{-1}$, which means that salts were severely accumulated in the uppermost soil layers. Therefore, the calibration of the model of electrical conduction in soil (Eqs. 10 and 11), in which $\mathrm{EC}_{\mathrm{w}}$ should be increased step by step from about 1 to $20 \mathrm{dS} \mathrm{m}^{-1}$ (Wang et al., 2005) could not be practiced in the laboratory.

The second chance to take soil samples came on 19 Sep. 2007, when the $\mathrm{EC}_{\mathrm{SAT}}$ of the surface soil collected around P3 was $4.5 \mathrm{dS} \mathrm{m}^{-1}$ (Fig. 4), while the EC of the groundwater measured at the well \#2 was $2.2 \mathrm{dS} \mathrm{m}^{-1}$ and depth to the water table was $67 \mathrm{~cm}$. The soil sample collected in the field seems to have been too much salinized to use for identifying the model parameters. Therefore, in order to identify the parameters, it seems necessary to devise an experimental technique with which the soil sample is desalted.

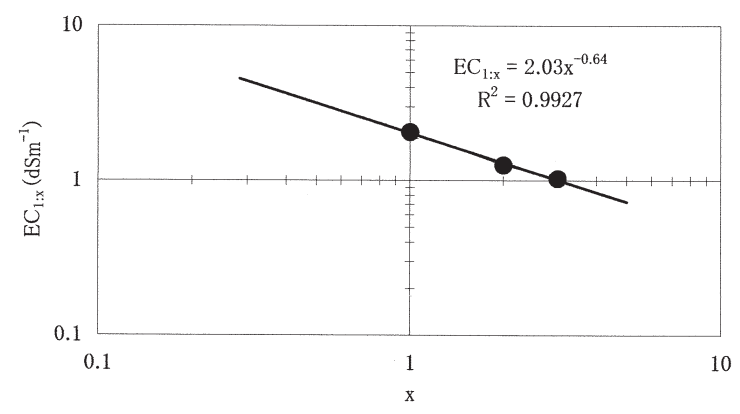

Fig. 4. Relationship between EC and $x$ for the soil sampled around P3 on 19 Sep. 2007. The left and right ends of the regression line segment corresponds to the saturation or $x=0.28$ and $x=5$, respectively. 
Thus, for the present, the results obtained for the soil of the Togtoh experimental field are given as the alternatives (Wang et al., 2006). They are not expected too much different from the ones for the Pingbu soil, because both soils are alluvial soils originated from the Yellow River.

$$
\begin{aligned}
& \theta=1.65 \times 10^{-5} K_{a}^{3}-9.91 \times 10^{-4} K_{a}{ }^{2}+3.32 \times 10^{-2} K_{a}-4.8 \times 10^{-2} \\
& \mathrm{EC}_{\mathrm{a}}=\mathrm{EC}_{\mathrm{w}} \theta(1.513 \theta-0.074)+0.08 \quad\left(\mathrm{dS} \mathrm{m}^{-1}\right) \\
& \quad\left(0.15<\theta<0.4,0.15<\mathrm{EC}_{\mathrm{a}}<1.5 \mathrm{dS} \mathrm{m}^{-1}\right)
\end{aligned}
$$

where every value of EC was normalized to a temperature of $25^{\circ} \mathrm{C}$.

\section{EVAOPORATION MEASUREMENT}

\section{Methods}

Meteorological and hydrological variables that are indispensable for monitoring water movement in the soil profile are precipitation and evaporation. In this experimental field, evaporation is measured by the Bowen ratio method except for the winter days when the surface soil freezes and/or thaws during the course of a day (Kaneko et al., 2006). The aerodynamic method is used for such exceptional days.

\section{Bowen ratio method}

The energy balance of the soil surface is expressed as

$$
R_{\mathrm{N}}-G=H+\lambda E
$$

where $R_{\mathrm{N}}=$ net radiation, $G=$ ground heat flux, $H=$ sensible heat flux, $E=$ evaporation rate, $\lambda=$ latent heat of vaporization. Eq.(15) can be rewritten in the form

$$
\lambda E=\frac{\left(R_{\mathrm{N}}-G\right)}{1+\beta}
$$

where $\beta \equiv H / \lambda E$ is the Bowen ratio.

Assuming that the transfer coefficients of heat and water vapor in the surface air layer are equal, the Bowen ratio $\beta$ can be estimated from an approximate equation

$$
\beta=\gamma \frac{T_{2}-T_{1}}{e_{2}-e_{1}}
$$

where $T_{i}(i=1,2)=$ air temperature at height $h_{i}, e_{i}=$ water vapor pressure at height $h_{i}, \gamma=$ psychrometer constant.

\section{Aerodynamic method}

The aerodynamic method relies on the existence of relations between fluxes and gradients of the forms described below (Kaneko et al., 2006).

$$
\text { Momentum: } \tau=\rho u_{*}^{2}=K_{\mathrm{M}} \rho \frac{\Delta u}{\Delta z}
$$

$$
\text { Water vapor: } E=-K_{\mathrm{V}} \frac{\Delta \rho_{\mathrm{V}}}{\Delta z}
$$

where $\rho=$ density of air $\left(\fallingdotseq 1.06 \mathrm{~kg} \mathrm{~m}^{-3}\right.$ at $\left.1500 \mathrm{~m} \mathrm{ASL}\right)$, $\Delta u / \Delta z=$ vertical gradient of wind speed, $\Delta \rho_{\mathrm{v}} / \Delta z=$ vertical gradient of water vapor density, $u_{*}=$ friction velocity, $K_{\mathrm{M}}=$ eddy diffusivity of momentum, $K_{\mathrm{V}}=$ eddy diffusivity of water vapor.

If it is assumed that $K_{\mathrm{M}}=K_{\mathrm{V}}$, the combination of Eqs. (18) and (19) yields

$$
E=-\frac{\Delta \rho_{\mathrm{v}}}{\Delta u} \quad u_{*}^{2}=-\rho \frac{\Delta q}{\Delta u} u_{*}^{2}
$$

where $q=$ specific humidity.

Since the surface is bare of plants in winter, when this method is used, the vertical gradient of wind speed can be written as

$$
\frac{\Delta u}{\Delta z}=\frac{u_{*}}{\kappa z} \phi_{\mathrm{M}}
$$

where $\kappa=$ von Karman constant $(=0.4), \phi_{\mathrm{M}}=$ dimensionless stability function. However, in this observation system, wind speed is measured at only one height, so the function $\phi_{\mathrm{M}}$ cannot be evaluated. Therefore it is assumed that the static stability is neutral, or $\phi_{\mathrm{M}}=1$, which does not seem too much different from the actual daytime conditions over the frozen soil. Then integrating Eq.(21) gives

$$
u=\frac{u_{*}}{\kappa} \ln \frac{z}{z_{0}}
$$

where $z_{0}=$ roughness length. Thus, if the roughness length is determined, substituting Eqs.(23) and (24)

$$
\begin{aligned}
& u *=\frac{\kappa u}{\ln \left(z / z_{0}\right)} \\
& \Delta u=u\left(z_{2}\right)-u\left(z_{1}\right)=\frac{u_{*}}{x} \ln \frac{z_{2}}{z_{1}}
\end{aligned}
$$

in Eq.(20) gives

$$
E=-\rho\left[q\left(z_{2}\right)-q\left(z_{1}\right)\right] u \frac{\kappa^{2}}{\ln \left(z / z_{0}\right) \ln \left(z_{2} / z_{1}\right)}
$$

where $z=$ wind speed measurement height, $z_{1}, z_{2}$ : humidity measurement heights.

\section{Calibration}

Bowen ratio method

Although psychrometer constant, $\gamma \equiv C_{\mathrm{p}} p / 0.622 \gamma$ where $C_{\mathrm{p}}=$ specific heat at constant pressure and $p=$ air pressure, is proportional to $p$, air pressure is not measured in the experimental field (Table 2). Therefore, a global average of $846 \mathrm{hPa}$ at $1500 \mathrm{~m}$ ASL is used. So a typical value for $\gamma$ is $0.55 \mathrm{hPa} \mathrm{K}^{-1}$.

Since air temperature and humidity are measured at only two heights in this field (Table 2), the accuracy of the measurements of $T_{i}$ and $e_{i}$ or $q_{i}(i=1,2)$ is essential to estimate the Bowen ratio accurately using Eq.(17). Therefore, before installing the sensors on the pole, a comparative measurement of air temperature and humidity with the two thermo-hygrometers mounted on the same arm was carried out in the experimental field for a full day 19-20 Sep. 2007. The results obtained are as follows:

$$
\text { Air temperature }\left({ }^{\circ} \mathrm{C}\right): T_{2} \text { (corrected) }
$$$$
=1.006 T_{2} \text { (measured) }-0.26
$$ 
Relative humidity (\%): $R H_{2}$ (corrected)

$$
=1.010 \mathrm{RH}_{2} \text { (measured) }-0.33
$$

Here the sensors installed at $4.3 \mathrm{~m}$ and $1.8 \mathrm{~m}$ AGL were numbered 1 and 2, respectively, and $T_{2}$ and $R H_{2}$ indicate the measurements made with the sensors designated No. 2. The sensors designated No. 1 were regarded as the standard ones (Fig. 5).
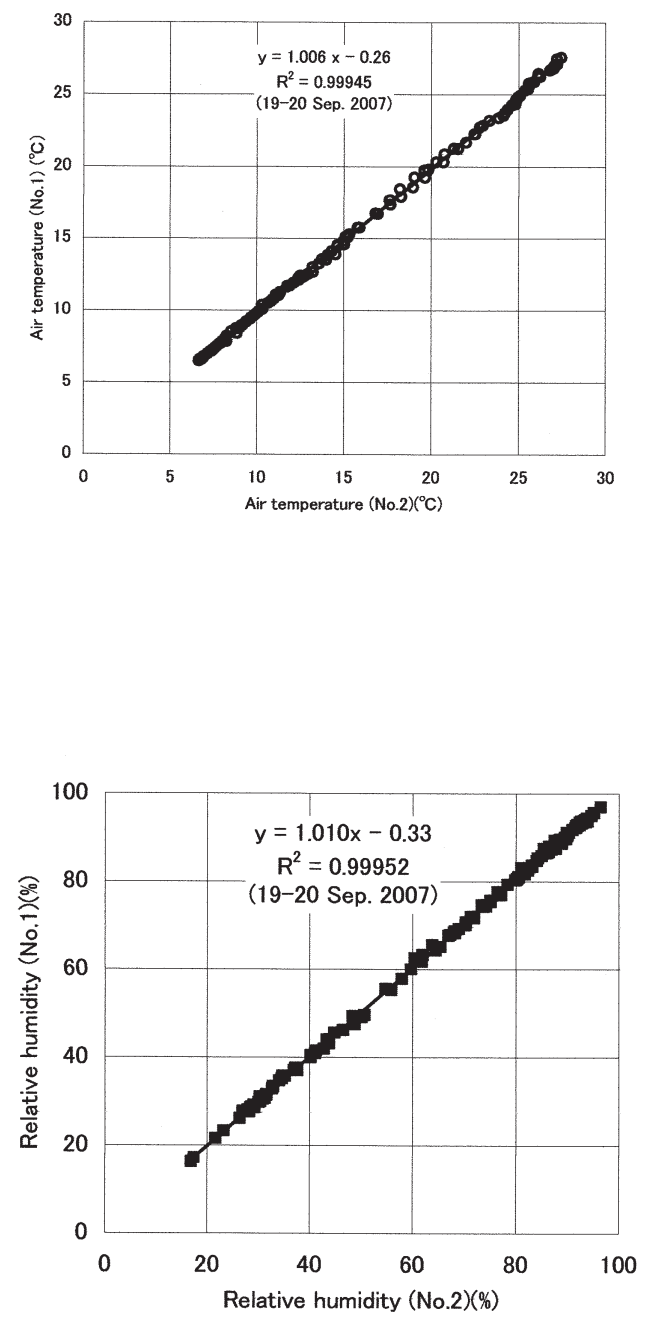

Fig. 5. Results of comparative measurements of (upper) air temperature and (lower) relative humidity with the two thermo-hygrometers mounted on the same arm.

Aerodynamic method

Eq.(25) is rewritten as

$$
E=B u \rho\left[q\left(z_{1}\right)-q\left(z_{2}\right)\right]
$$

where

$$
B \equiv \frac{\kappa^{2}}{\ln \left(z / z_{0}\right) \ln \left(z_{2} / z_{1}\right)}
$$

In this observation system, $z=6.0 \mathrm{~m}, z_{1}=1.8 \mathrm{~m}$, and $z_{2}=4.3 \mathrm{~m}$ (Table 2), so $B$ is a function of only roughness length $z_{0}$. A possible range of $z_{0}$ of the field without vegetation in winter may be from $10^{-4} \mathrm{~m}$ to $10^{-2} \mathrm{~m}$. Thus, the value for $B$ is estimated to range from about $2 \times 10^{-2}$ to $3 \times 10^{-2}$.

When the aerodynamic method is used to estimate the evaporation from the soil surface in winter, the value for $z_{0}$ should be identified in advance by comparing measurements of evaporation made by the aerodynamic method with those obtained by the Bowen ratio method in the field without vegetation during a unfrozen period.

\section{CONCLUDING REMARKS}

The observation system installed in the Pingbu experimental field for measuring meteorological and hydrological elements relevant to salinization and alkalization of soils was described in detail. Principles of measuring such elements were examined and their limitations also were pointed out in case of necessity. Furthermore, careful consideration was given to the system so that the system could measure such elements as accurately as possible. A comparison of the physical properties of the soil in this field with those in the Togtoh experimental field suggested that the Pingbu soil is more susceptible to salinization than the Togtoh soil is.

The observation system, however, cannot give us sufficient information on the spatial variations in salinity in the field. Furthermore, elements relevant to alkalization and biological reclamation of surface-irrigated fields (Wang et al., this issue) cannot be observed with this system. Therefore, in order to conduct these experiments, it is necessary to make intensive observations frequently in and around the field.

\section{ACKNOWLEDGEMENTS}

The authors wish to thank Prof. X. Li of the Cold and Arid Regions Environmental and Engineering Research Institute, CAS, for his cooperation. They would also like to thank the local government of Pingbu village for giving support to their experiments.

This research is funded by a Grant-in-Aid for Scientific Research of the Japan Society for the Promotion of Science (JSPS) during period from 2007 to 2009 (No. 19405039).

\section{REFERENCES}

Dirksen, C. 1999 Soil Physics Measurements. GeoEchology paperback, Catena Verlag GMBH, Reiskirchen (Germany)

Jury, W. A. and R. Horton 2004 Soil physics. John Wiley \& Sons, New Jersey

Kaneko, T., T. Kobayashi, W. Wang, W. He and H. Cho 2006 An evaluation of the overwinter loss of the water irrigated in late autumn in the upper reaches of the Yellow River. $J$. Japan Soc. Hydrol. \& Water Resour., 19: 465-474

Kobayashi, T., W. Wang, Y. Ikawa, H. Cho and W. He 2006a An easily measurable and practical index of soil salinity. $J$. Japan Soc. Hydrol. \& Water Resour., 19: 183-188

Rhoades, J. D., P. A. C. Raats and R. J. Prather 1976 Soil electrical conductivity and soil salinity. New formulations and calibrations. Soil Sci. Soc. AM. J., 40: 651-655

Rhoades, J. D. 1982 Soluble salts. In: "Methods of soil analysis Part 2, chemical and microbiological properties", Agronomy Monograph 9, ed. by Page, A. L. et al., pp. 167-178

Takahashi, H. 1970 Electro-magnetism. Shokabô, Tokyo. (in Japanese)

Topp, G. C., M. Yanuka, W. D. Zebchuk and S. Zegerin 1988 
Determination of electrical conductivity using time domain reflectometry: soil and water experiments in coaxial line. Water Resour. Res., 24: 945-952

Vogeler, I., S. Green and B. E. Clothier 2005 Time domain reflectometry as an alternative in solute transport studies. In "Soil-Water-Solute Process Characterization. An Integrated Approach" ed. by J. A.-Benedi and R. M.-Carpena CRC Press, London, pp. 357-390

Yasutake, D., D. Araki, M. Kitano, W. Wang, K. Urayama, H. Cho and T. Kobayashi 2008 Experiments on the control of salinity and sodicity in surface-irrigated fields in the upper Yellow River valley (III). The state of salinization and alkalization in and around the experimental field. J. Fac. Agr. Kyushu Univ., 52: 265-270

Yanuka, M., G. C. Topp, S. Zeigelin and W. D. Zebchuk 1988 Multiple reflection and attenuation of time domain reflec- tometry pulses: theoretical considerations for applications to soil and water. Water Resour. Res., 24: 939-944

Wang, W., E. Watanabe, T. Kobayashi, H. Cho, W. He and N. Mohri 2005 A method for measuring soil solution electrical conductivity in the field using TDR. J. Japan Soc. Hydrol. \& Water Resour., 18: 55-63

Wang, W., T. Kobayashi, H. Cho and W. He 2006 Simultaneous and continuous measurement of soil water content and solution electrical conductivity in an irrigated cornfield using TDR. J. Japan Soc. Hydrol. \& Water Resour., 19: 350-359

Wang, W., T. Kobayashi, D. Yasutake, M. Kitano, H. Cho, T. Araki and $\mathrm{H}$. Yoshikoshi 2008 Experiments on the control of salinity and sodicity in surface-irrigated fields in the upper Yellow River vally (I) Objectives and Methodology. J. Fac. Agr. Kyushu Univ., 52: 251-256 